\title{
WHOOPING CRANES IN 1987 ANOTHER YEAR OF PROGRESS
}

ERNIE KUYT, Canadian Wildlife Service, Room 210, 4999 - 98 Avenue, Edmonton, Alberta. T6B $2 \times 3$

The 1980s have been the decade of truth for Whooping Cranes.

In 1980 and 1981 exceedingly dry conditions in Wood Buffalo National Park (WBNP) contributed greatly to grave forest fire risks. In contrast to 1980 when most serious forest fires in northern Alberta occurred in May, the most disastrous part of the 1981 fire season did not begin until early August. ${ }^{1}$ Lightningcaused fires erupted on 14 August 1981 in the Whooping Crane summer range in WBNP. Sweeping through woodland, brush and drying wetlands, the fires burned an estimated $70 \%$ of the cranes' breeding range. Canadian Wildlife Service (CWS) file reports covering the 1981 field season make frequent references to drying conditions of breeding habitat and concomitant losses of Whooping Crane chicks.

In early August 1981 only three chicks were alive but fortunately all of them survived the fires by taking shelter with their parents in the few wet areas that had remained unburned. The 1981 year class

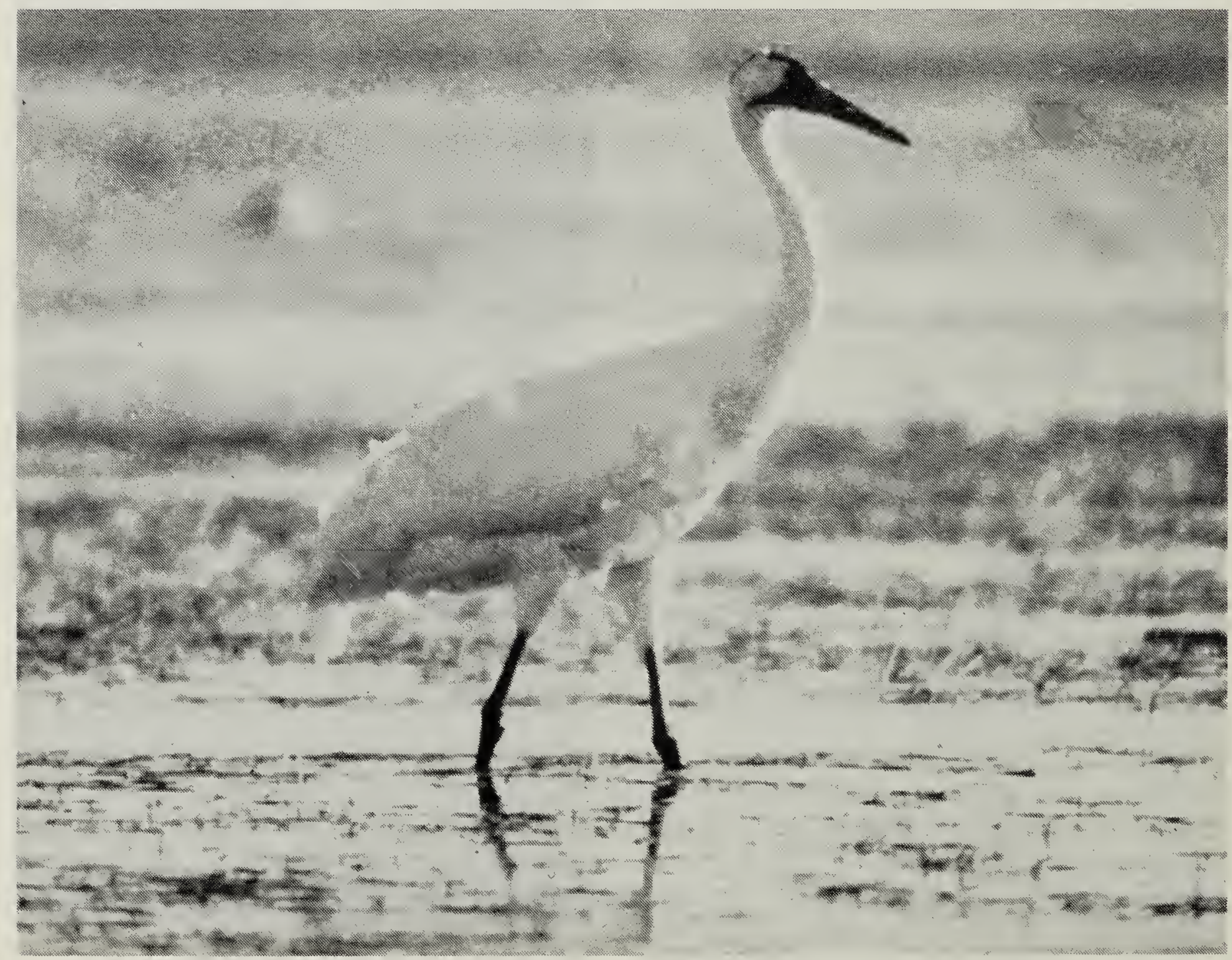


was further reduced when two of their number died after collisions with power lines in Saskatchewan (October 1981) and Texas (October 1982).

After the low water level years of 1980 and 1981, water conditions in the Whooping Crane breeding range in WBNP improved, and these reversals in habitat conditions, combined with management techniques, most likely are responsible for the recent population increase (Fig. 1).

During the 1985-1987 field seasons increasing use was made of field tests to determine viability of eggs left in nests after the annual collection of surplus eggs. The data show that during this period, hatching success of eggs left in nests and tested as live increased by $15-19 \%$. Undoubtedly production of juveniles during the past 3 years was also enhanced.

In 1987, CWS aerial surveys over the Whooping Crane breeding range accounted for 32 nests, all but 3 containing 2 eggs. This all-time record of nests included first-time nesting efforts by three newly formed pairs and two of these had only a single egg each. Each of these two pairs was made up of a colour-banded 3-year old male and an unbanded bird. One of the pairs failed to hatch its egg but the other pair's egg hatched and the chick is still alive. It is the first record of successful reproduction by a 3-year old male Whooping Crane. In 1986 a pair of 3 and 4-year old cranes produced two fertile eggs but sex of these birds is not known.

The third nest with only a single egg in 1987 is a story in itself. The nest was discovered near the Sass River, Northwest Territories (NWT) on 4 May 1987 and, although a crane was on the nest, there was no egg. On the next survey of 7 May a single egg was in the nest, somewhat surprising, as the clutch should have been completed by then. On 10 May the nest was empty although a crane had been on it. A crane was again seen on the nest in incubating position at the conclusion of the day's survey. The final survey on 18 May (before the 21 May collection of surplus eggs) again showed a crane on the nest and a second bird nearby. There was no egg in the nest. On 21 May a live surplus egg, collected 10 minutes earlier from a nearby nest, was placed in this nest. At the conclusion of the egg collection the bird was incubating the egg. This egg hatched and the chick, colour-banded on 6 August wintered on the Aransas National Wildlife Refuge (ANWR) in Texas together with its foster parents. Its sibling from the nearby nest wintered not far away with the two young birds' natural parents.

After the surplus egg pickup 34 eggs remained in 31 nests. Both eggs were left in three nests since two were late nests and the third was attended by skittish adults which were left undisturbed. On 17 and 20 June a total of 27 chicks was seen. Two eggs which failed to hatch were collected and several eggs or young chicks (including single chicks or eggs from two of the three two-egg clutches) had disappeared. By 8 August 26 chicks were still alive (including a single chick from the remaining two-egg nest) and of these, 21 were colour-banded. Four chicks remained unbanded and a fifth chick suffered a leg injury just before being captured and died, most likely as a result of the injury. It was only the second casualty possibly related to banding activities involving 118 bandings over the past 11 years.

All 25 chicks safely migrated to Texas although one of them apparently separated from its parents during migration. This banded chick was seen about $50 \mathrm{~km}$ southeast of Amarillo, Texas. Another bird, a colour-banded yearling, spent the winter about $80 \mathrm{~km}$ north of ANWR. Last winter the same bird spent its first winter with Sandhill Cranes in Oklahoma while its parents were on the Aransas refuge. 

WHOOPING CRANE FLOCK, 1967-1987.

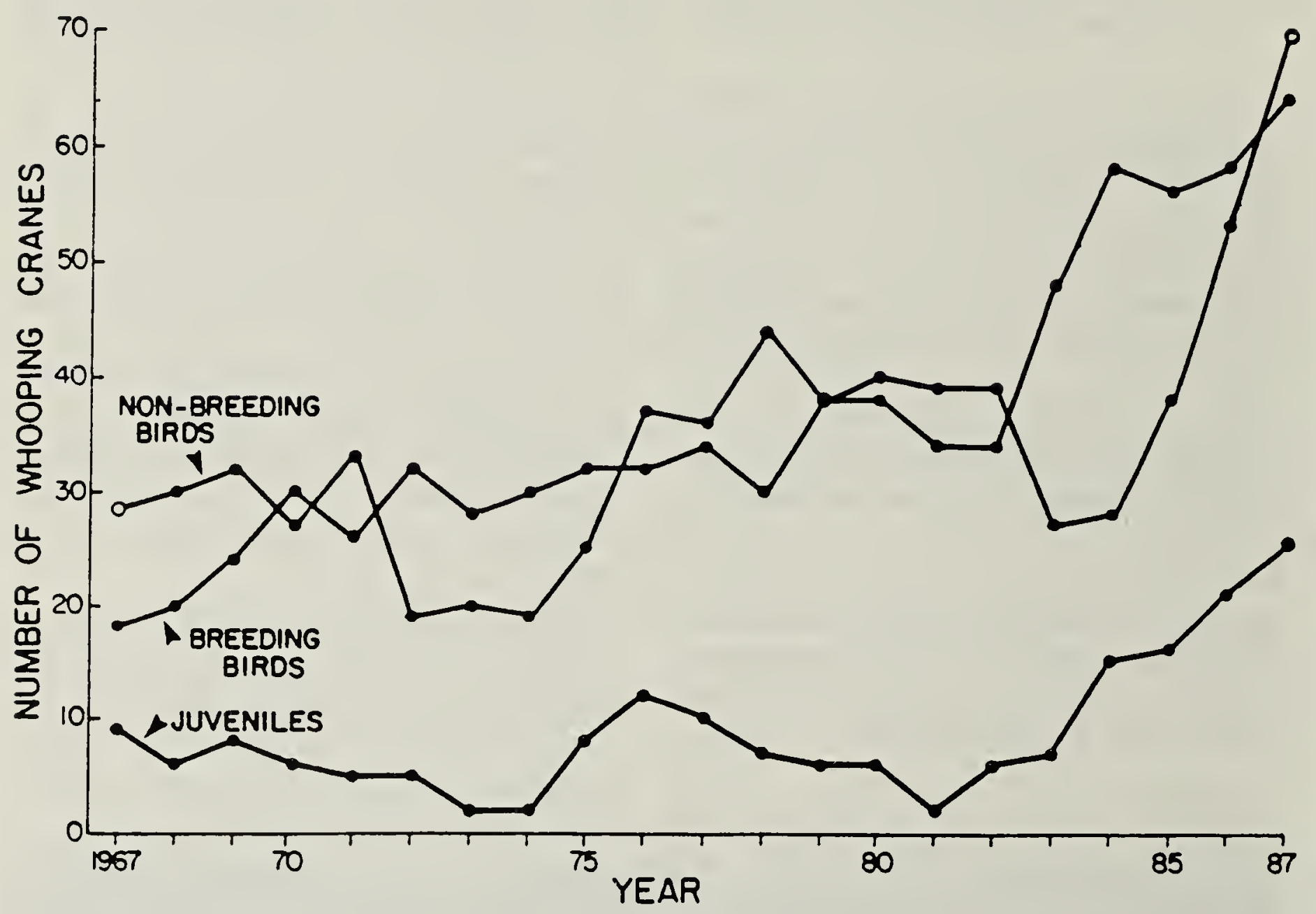

That bird is a noted traveller and individualist as it managed to find its way back to WBNP where it was seen in May 1987. Surprisingly it then continued its northward flight and was reported and photographed near Yellowknife, NWT, by D.C. Heard of the NWT Fish and Wildlife Service. Could this be an example of pioneering effort in Whooping Cranes?

Annual population figures are always made available by the staff of ANWR and T. Stehn (pers. comm.) advised that 134 Whooping Cranes were accounted for in Texas by 10 December 1987. As 109 Whooping Cranes began the 1987 spring migration and 25 chicks returned south amongst the 134 birds, the happy news is that none of the 109 birds died during summer. According to Stehn, this is only the eighth time in the last 50 years that summer mortality has not occurred. Numbers of nonbreeding birds (including juveniles), breeding birds and juveniles arriving at ANWR in fall during the past 20 years are shown in Fig. 1.

Egg collecting (which began in 1967) and viability testing, as well as the colour banding program initiated in 1977 are carried out with great care by highly experienced crews. In over 587 nest visitations there has not been an instance of nest abandonment by incubating Whooping Cranes. Staff of the United States Fish and Wildlife Service, WBNP and volunteers have provided significant support to CWS, and these cooperative field studies are continuing to be of the greatest importance to the conservation of Whooping Cranes.

1 HARVEY, D.A., M.E. ALEXANDER and B. JANZ 1986. A comparison of fire-weather severity in Northern Alberta during the 1980 and 1981 fire seasons. For. Chronicle 62:507-513. 


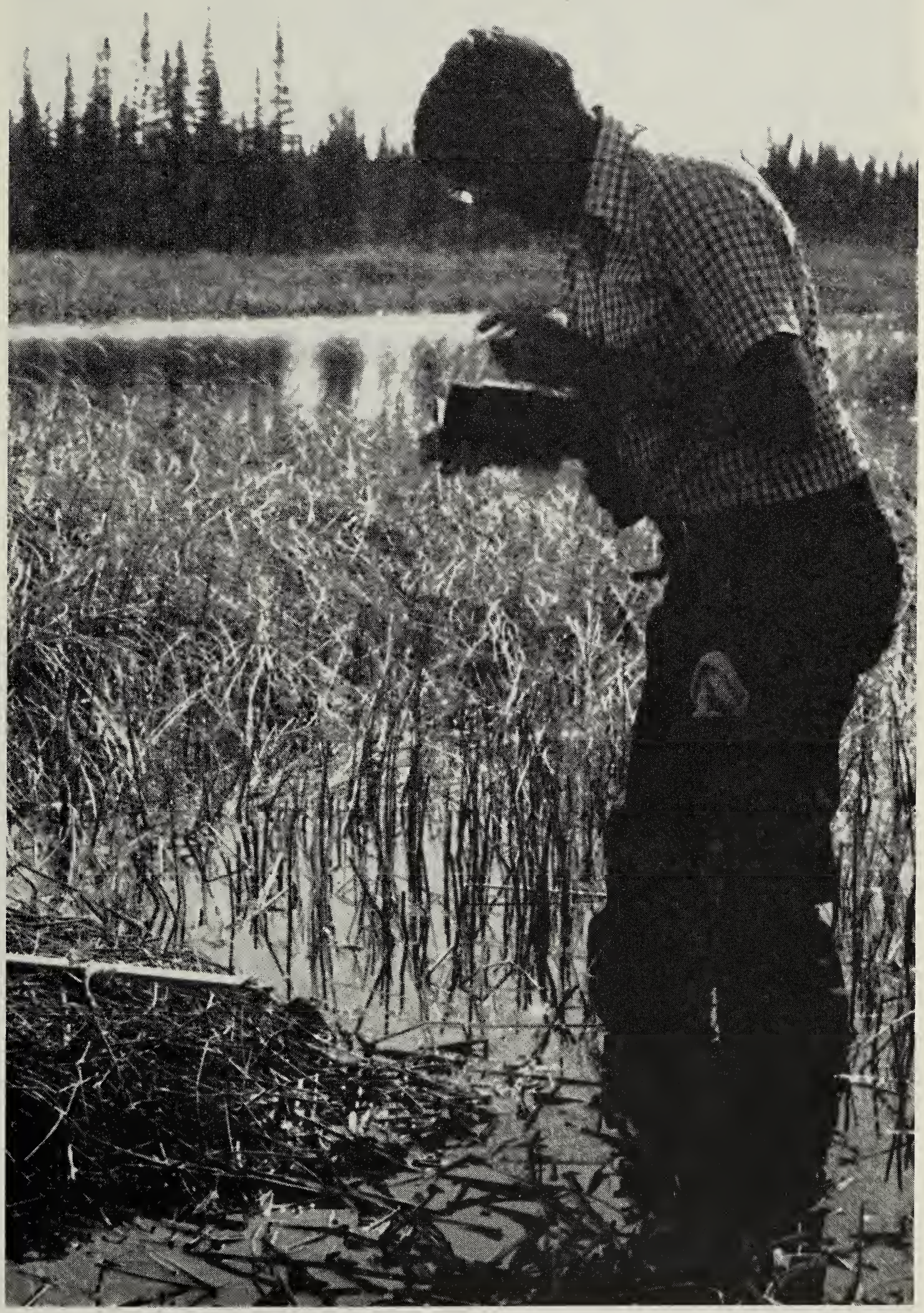

